\title{
OPTIMASI BESARAN FISIS YANG MEMPENGARUHI PROSES KONVERSI ENERGI (STUDI KASUS PERCOBAAN TARA KALOR MEKANIK DAN HUKUM JOULE)
}

\author{
Nani Yuningsih ${ }^{1, a)}$ \\ ${ }^{1}$ Politeknik Negeri Bandung, Jl. Terusan Gegerkalong Hilir, Ds. Ciwaruga, Kotak Pos 1234, Bandung \\ Email: a) nani.yuningsih@polban.ac.id
}

\begin{abstract}
Abstrak
Konsep Hukum kekekalan energi dapat diberikan melalui percobaan Tara Kalor Mekanik dan Percobaan Hukum Joule. Percobaan Tara Kalor Mekanik membuktikan konsep perubahan energi mekanik menjadi energi panas, sedangkan percobaan Hukum Joule membuktikan konsep perubahan energi listrik menjadi energi panas. Percobaan Tara Kalor Mekanik menggunakan 3 jenis calorimeter yaitu calorimeter tembaga kosong, calorimeter tembaga pejal, dan calorimeter aluminium pejal. Untuk mendapatkan perubahan energi mekanik menjadi energi panas yang optimum, calorimeter tembaga memerlukan kecepatan sudut lebih besar dibandingkan dengan calorimeter aluminium pejal. Kecepatan sudut optimum calorimeter tembaga kosong adalah $137 \mathrm{rpm}$, tembaga pejal $132 \mathrm{rpm}$, sedangkan aluminium pejal sebesar $113 \mathrm{rpm}$. Hal ini sesuai dengan besarnya kapasitas panas bahan calorimeter yang digunakan. Ketidaklinieran harga arus dengan perubahan panas disebabkan karena kalorimeter yang digunakan tidak murni bersifat adiabatik akibatnya ketika diberikan harga arus yang besar, suhu air pada kalorimeter cepat naik dan terjadi penyerapan suhu oleh lingkungan semakin besar. Sedangkan saat pemberian arus rendah, lebih kecil dari 1,5 A, suhu air pada kalorimeter mengalami kenaikan dengan waktu yang cukup lama. Dari hasil analisis ini disarankan apabila menggunakan arus yang kecil, waktu pemanasan perlu diperbesar. Dengan demikian dapat direkomendasikan pemberian harga arus yang optimum adalah pada pemberian arus sebesar 1,5 $\mathrm{A}-2,5 \mathrm{~A}$, dengan ratio $\mathrm{Q} / \mathrm{W}$ mendekati $100 \%$.
\end{abstract}

Kata-kata kunci: kalorimeter, Tarakalor mekanik, Hukum Joule

\begin{abstract}
The concept of energy conservation law is given through the experiment of the equivalence of mechanical heat and the experiment of Joule's Law. The experiment of the equivalence of mechanical heat proves the concept of changing mechanical energy into heat energy, while the Joule's Law experiment proves the concept of changing electrical energy into heat energy. The experiment of the equivalence of mechanical heat uses three types of calorimeters that are water calorimeter, copper-block calorimeter, and aluminum-block calorimeter. To obtain mechanical energy changes to maximum heat energy, copper-block calorimeters require greater angular velocity than aluminum-block calorimeters. The optimum angular velocity of water calorimeter is $137 \mathrm{rpm}$, copper-block is $132 \mathrm{rpm}$, and aluminumblock is $113 \mathrm{rpm}$. This corresponds to the heat capacity of the calorimeter material used. The data obtained in Joule's law experiments of nonlinearity between the current given by the Q / W ratio is due to several factors. This is because the calorimeter used is not pure adiabatic, therefore when given the large currents, water temperature on the calorimeter rise fast, and absorption of temperature by the environment is greater. While the current smaller than $1.5 \mathrm{~A}$, water temperature on the calorimeter has increased in a long time. From the results of this analysis, it is suggested when using a small current,
\end{abstract}


and the heating time needs to be increased. It can be recommended that the maximum current is given at 1.5 A-2.5 A, with a Q / W ratio approaching $100 \%$.

Keywords: calorimeter, Equivalence of Mechanical Heat, Joule's Law

\section{PENDAHULUAN}

Dalam melaksanakan pembelajaran di laboratorium perlu terus menerus dilakukan pengkajian dan penelitian terhadap alat praktikum sehingga terjadi proses pembelajaran yang optimal.

Salah satu pokok bahasan yang ada pada kegiatan praktikum di laboratorium Fisika Politeknik Negeri Bandung adalah konsep konversi energi. Konsep konversi energi antara lain dapat diamati pada percobaan tara kalor mekanik dan hukum Joule. Sejauh ini berdasarkan hasil pengamatan, kedua percobaan mengalami kendala, khususnya pada peralatan pendukung, sehingga hasilnya belum optimal. Untuk mendapatkan kondisi yang optimal, perlu dilakukan penelitian dengan mengamati faktor yang berpengaruh pada konsep tara kalor mekanik dan hukum joule. Telah dilakukan analisis penyimpangan besaran yang berpengaruh pada perubahan energi listrik menjadi energi panas [1]. Penyimpangan yang terjadi adalah faktor massa air yang diberikan pada kalorimeter, diperoleh ketidaklinieran antara masa dengan perubahan panas yang terjadi. Faktor lain yang dapat mempengaruhi tersebut dapat ditinjau berdasarkan kondisi alat atau besaran-besaran yang mempengaruhi besaran-besaran yang berpengaruh pada konsep tara kalor makanik dan hukum joule.

\section{Tinjauan Percobaan Tara Kalor Mekanik}

Percobaan Tara Kalor Mekanik bertujuan membuktikan hukum kekekalan energi pada proses perubahan usaha mekanik menjadi kalor. Perangkat alat yang digunakan dapat dilihat pada GAMBAR 1 .

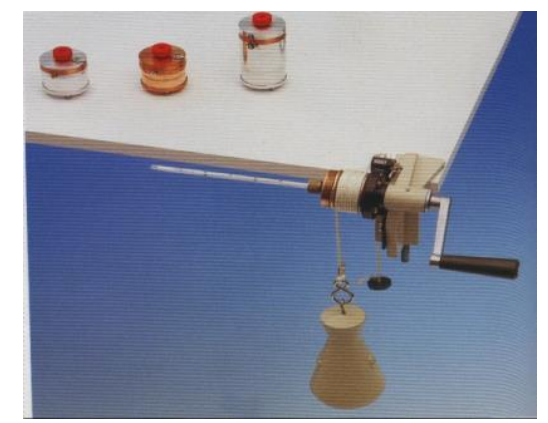

GAMBAR 1. Perangkat Alat Percobaan Tara Kalor Mekanik [2]

Silinder yang dililit tali berbeban $\mathrm{Mg}$, jika diputar sebanyak $\mathrm{N}$ putaran tanpa mengakibatkan beban naik, akan menyerap usaha mekanik sebesar

$$
W=M g N \pi d
$$

Dimana $\mathrm{d}=$ diameter kalorimeter, $\mathrm{M}=$ massa beban yang dililit pada tali, $\mathrm{g}=$ percepatan gravitasi, dan $\mathrm{N}$ = banyaknya putaran.

Usaha tersebut diubah menjadi kalor $(\mathrm{Q})$ yang digunakan untuk mengubah suhu kalorimeter serta isinya $(\Delta \mathrm{T})$, sehingga memenuhi persamaan :[3]

$$
\begin{aligned}
& W=Q \\
& Q=C . \Delta T
\end{aligned}
$$

dengan $\mathrm{C}=$ kapasitas panas kalorimeter 


\section{Tinjauan Percobaan Hukum Joule}

Percobaan Hukum Joule bertujuan membuktikan keberlakuan hukum kekekalan energi pada proses konversi energi listrik menjadi kalor. Perangkat alat yang digunakan dapat dilihat pada GAMBAR 2.
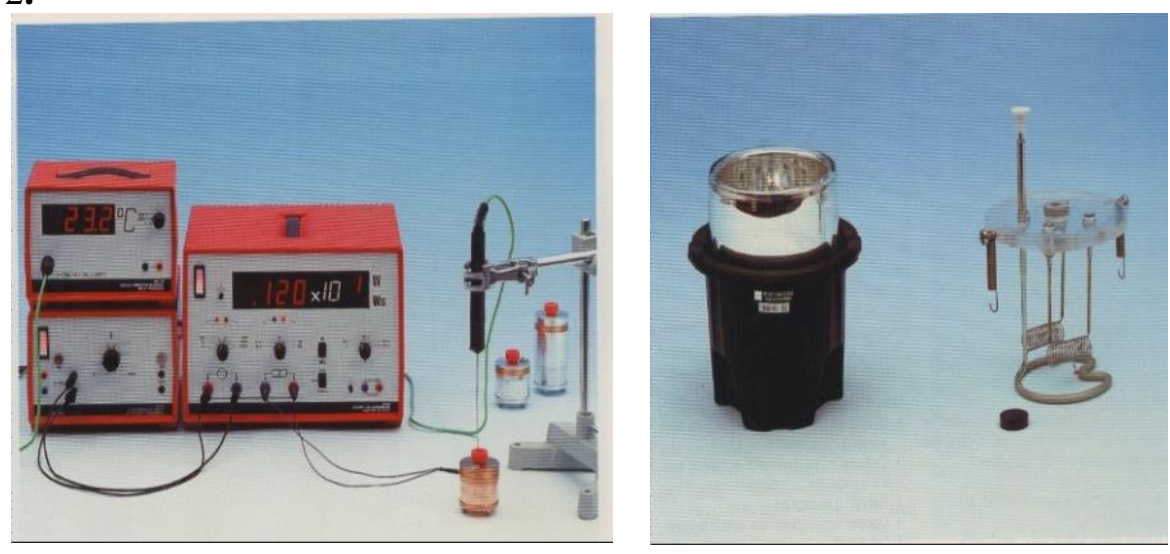

GAMBAR 2. Perangkat Alat Percobaan Hukum Joule

Energi listrik yang terjadi pada kawat yang dialiri arus listrik dapat diubah menjadi kalor. Energi listrik karena adanya beda potensial $\mathrm{V}$ pada kawat sehingga mengalir arus i pada selang waktu t, adalah $[4,5,6]$ :

$$
W(t)=V i t
$$

Dimana $\mathrm{W}=$ energi listrik, $\mathrm{V}=$ tegangan listrik yang diberikan kawat, $\mathrm{i}=$ kuat arus listrik yang mengalir pada kawat, $\mathrm{t}=$ waktu selama arus listrik mengalir pada kawat. Sedang kalor yang terjadi dalam kalorimeter tempat kawat berada adalah

$$
Q(t)=m c \Delta T
$$

Dengan $\mathrm{m}=$ massa medium (misalnya air pengisi kalorimeter), $\mathrm{c}=$ panas jenis medium tersebut, dan $\Delta \mathrm{T}=$ perubahan suhu yang terjadi.

Untuk mendapatkan $\Delta \mathrm{T}$, baik Tara kalor mekanik maupun Hukum Joule, harus memenuhi persamaan koreksi Newton (k) laju pendingingan, dimana pada proses perubahan usaha mekanik menjadi kalor, maupun proses perubahan energi listrik menjadi kalor, ada pengaruh temperatur ruangan, yang memenuhi perumusan hukum Newton laju pendinginan $[1,7,8]$.

\section{METODE PENELITIAN}

Metode yang digunakan dalam penelitian ini adalah metode analisis deskriptif. Instrumen penelitian terdiri dari perangkat alat percobaan Tara Kalor Mekanik untuk mengamati perubahan energi mekanik menjadi energi panas dan perangkat alat percobaan Hukum Joule untuk mengamati perubahan energi listrik menjadi energi panas. Energi mekanik dihasilkan dari kalorimeter yang dipasang pada perangkat alat tara kalor mekanik. Dalam penelitian ini diamati 3 kalorimeter yaitu tembaga kosong yang diisi dengan air, tembaga pejal, dan alumunium pejal. Waktu pemanasan dan waktu pendinginan kalorimeter pada konversi energi mekanik menjadi energi panas masing-masing 120 detik dan 240 detik. Begitu juga pengamatan perubahan energi listrik menjadi energi panas digunakan kalorimeter dengan waktu pemanasan dan waktu pendinginan masing-masing 120 detik dan 240 detik, massa air 100 gram dengan variasi arus $0,5-3,0 \mathrm{~A}$, dan variasi tegangan 1,4 -8,0 V. 


\section{HASIL DAN PEMBAHASAN}

\section{Tara Kalor Mekanik}

Dalam penelitian ini yang diamati 3 kalorimeter yaitu, tembaga kosong, diisi dengan air, tembaga pejal, dan alumunium pejal. Spesifikasi alat dan besar besaran untuk proses perubahan energi mekanik menjadi energi panas dapat dilihat pada TABEL 1.

TABEL 1. Spesifikasi alat Tara Kalor Mekanik dan Jenis-jenis kalorimeter

\begin{tabular}{clccccc}
\hline NO & Jenis Kalorimeter & $\begin{array}{c}\text { Diameter, d } \\
(\mathbf{m m})\end{array}$ & $\begin{array}{c}\text { Kapasitas panas } \\
\text { kalorimeter, C } \\
(\mathbf{J} / \mathbf{K})\end{array}$ & $\begin{array}{c}\text { Waktu } \\
\text { pemanasan } \\
(\mathbf{d e t i k})\end{array}$ & $\begin{array}{c}\text { Waktu } \\
\text { Pendinginan } \\
(\mathbf{d e t i k})\end{array}$ & $\begin{array}{c}\text { Massa } \\
\text { Beban } \\
(\mathbf{k g})\end{array}$ \\
\hline 1 & Tembaga kosong & 46,6 & 40 & 120 & 240 & 2 \\
2 & Tembaga pejal & 47 & 264 & 120 & 240 & 5 \\
3 & Aluminium pejal & 46,86 & 188 & 120 & 240 & 5 \\
\hline
\end{tabular}

Kalorimeter Tembaga Kosong

Kalorimeter tembaga kosong diisi dengan air, kemudian diputar selama 120 detik dan digantungi beban $2 \mathrm{Kg}$. Dengan memasukkan factor koreksi lingkungan (Koreksi Newton) diperoleh data perubahan suhu yang terjadi untuk beberapa nilai jumlah putaran $(\mathrm{N})$. Dari jumlah putaran yang dilakukan selama selang waktu tertentu dapat diperoleh kecepatan sudut putarannya. Dengan waktu putar 120 detik diperoleh hubungan antara kecepatan sudut dengan kenaikan suhu seperti tampak pada GAMBAR 3.

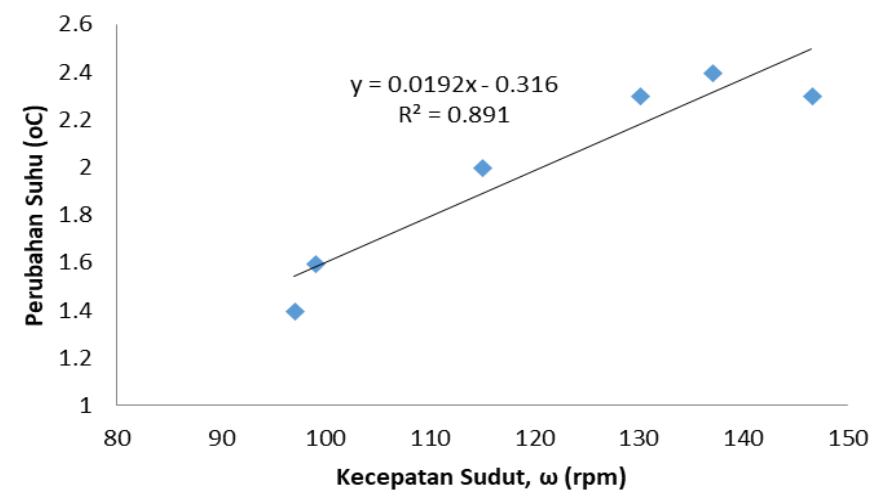

GAMBAR 3. Pengaruh kecepatan sudut pada perubahan suhu kalorimeter tembaga kosong

TABEL 2. Hubungan kecepatan sudut dengan perbandingan $\mathrm{Q} / \mathrm{W}$

\begin{tabular}{ccccc}
\hline No. & $\begin{array}{c}\text { Jumlah putaran } \\
(\mathbf{N})\end{array}$ & $\begin{array}{c}\text { Kecepatan sudut } \\
(\mathbf{r p m})\end{array}$ & $\begin{array}{c}\text { Perubahan Suhu } \\
\left({ }^{\mathbf{0}} \mathbf{C}\right)\end{array}$ & Perbandingan Q/W \\
\hline 1 & 194 & 97 & 1.4 & $86 \%$ \\
2 & 198 & 99 & 1.6 & $91 \%$ \\
3 & 231 & 115.5 & 1.82 & $92 \%$ \\
4 & 259 & 130 & 2 & $76 \%$ \\
5 & 274 & 137 & 2.4 & $99 \%$ \\
6 & 293 & 146.5 & 2.3 & $90 \%$ \\
\hline
\end{tabular}


Dari GAMBAR 3 diperoleh hubungan linier antara kecepatan sudut putar dengan perubahan suhu, dengan koefisien regresi 0,891 . Kondisi optimum untuk energi mekanik berubah menjadi energi panas diperoleh pada kecepatan sudut putar $137 \mathrm{rpm}$. Hubungan kecepatan sudut dengan perbandingan panas yang dihasilkan (Q) dengan usaha yang dilakukan (W) dapat dilihat pada TABEL 2.

\section{Kalorimeter Tembaga Pejal}

Kalorimeter tembaga pejal diputar selama 120 detik dan digantungi beban $5 \mathrm{Kg}$. Dengan memasukkan factor koreksi lingkungan (Koreksi Newton) diperoleh data perubahan suhu yang terjadi untuk beberapa nilai jumlah putaran $(\mathrm{N})$. Dari jumlah putaran yang dilakukan selama selang waktu tertentu dapat diperoleh kecepatan sudut putarannya. Dengan waktu putar 120 detik diperoleh hubungan antara kecepatan sudut dengan kenaikan suhu seperti tampak pada GAMBAR 4.

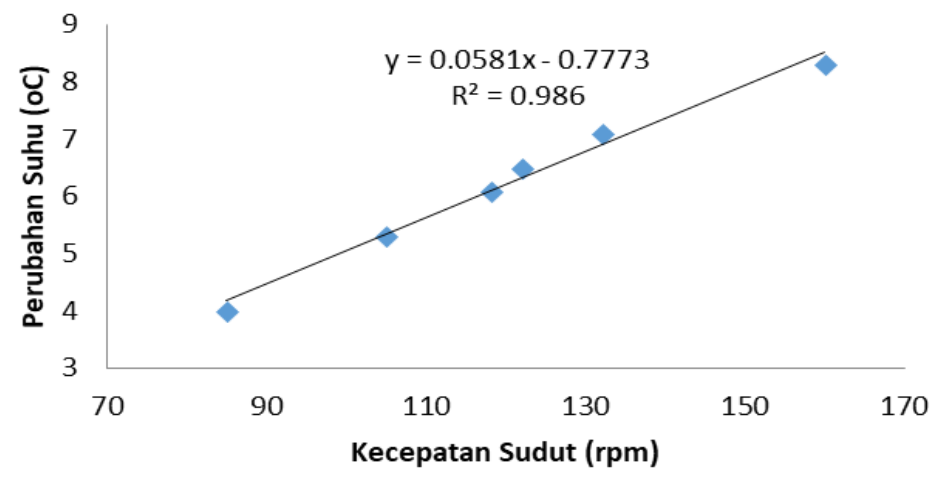

GAMBAR 4. Pengaruh kecepatan sudut pada perubahan suhu kalorimeter tembaga pejal.

Dari GAMBAR 4 diperoleh hubungan linier antara kecepatan sudut putar dengan perubahan suhu, dengan koefisien regresi 0,986 . Kondisi optimum untuk energi mekanik berubah menjadi energi panas diperoleh pada kecepatan sudut putar $132 \mathrm{rpm}$. Hubungan kecepatan sudut dengan perbandingan panas yang dihasilkan (Q) dengan usaha yang dilakukan (W) dapat dilihat pada TABEL 3.

TABEL 3. Hubungan kecepatan sudut dengan perbandingan $\mathrm{Q} / \mathrm{W}$ tembaga pejal

\begin{tabular}{ccccc}
\hline No. & $\begin{array}{r}\text { Jumlah putaran } \\
(\mathbf{N})\end{array}$ & $\begin{array}{c}\text { Kecepatan sudut } \\
(\mathbf{r p m})\end{array}$ & $\begin{array}{c}\text { Perubahan Suhu } \\
\left({ }^{\circ} \mathbf{C}\right)\end{array}$ & $\begin{array}{c}\text { Perbandingan } \\
\mathbf{Q} / \mathbf{W}\end{array}$ \\
\hline 1 & 170 & 85 & 4 & $87 \%$ \\
2 & 210 & 105 & 5,3 & $90 \%$ \\
3 & 236 & 118 & 6,1 & $95 \%$ \\
4 & 244 & 122 & 6,5 & $96 \%$ \\
5 & 264 & 132 & 7,1 & $97 \%$ \\
6 & 320 & 160 & 8,3 & $94 \%$ \\
\hline
\end{tabular}

\section{Kalorimeter Aluminium Pejal}

Kalorimeter aluminium pejal diputar selama 120 detik dan digantungi beban $5 \mathrm{Kg}$. Dengan memasukkan factor koreksi lingkungan (Koreksi Newton) diperoleh data perubahan suhu yang terjadi untuk beberapa nilai jumlah putaran $(\mathrm{N})$.

Dari jumlah putaran yang dilakukan selama selang waktu tertentu dapat diperoleh kecepatan sudut putarannya. Dengan waktu putar 120 detik diperoleh hubungan antara kecepatan sudut dengan kenaikan suhu seperti tampak pada GAMBAR 5. 


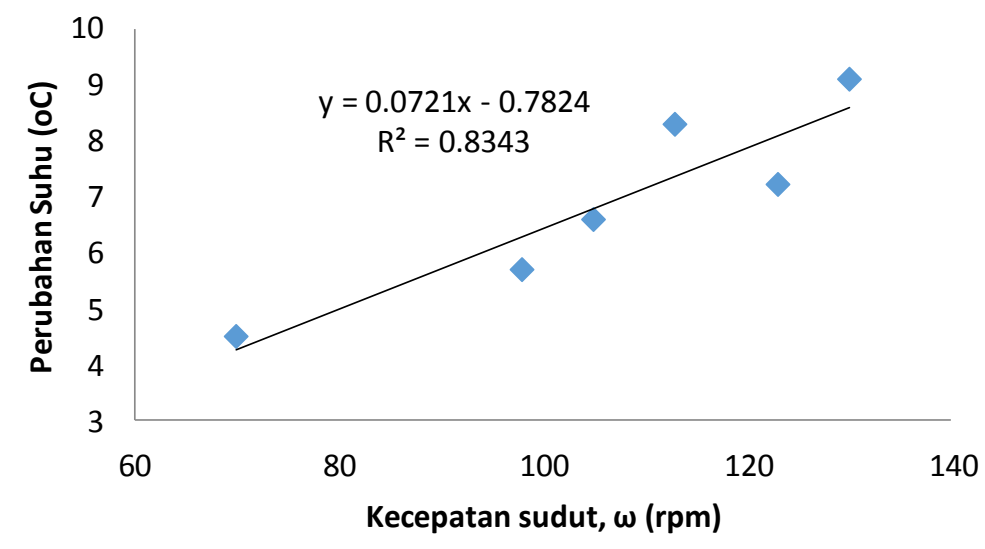

GAMBAR 5. Pengaruh kecepatan sudut pada perubahan suhu Kalorimeter aluminium pejal

Dari GAMBAR 5 diperoleh hubungan linier antara kecepatan sudut putar dengan perubahan suhu, dengan koefisien regresi 0,838. Namun demikian kondisi optimum untuk energi mekanik berubah menjadi energi panas diperoleh pada kecepatan sudut putar $113 \mathrm{rpm}$. Hubungan kecepatan sudut dengan perbandingan panas yang dihasilkan $(\mathrm{Q})$ dengan usaha yang dilakukan $(\mathrm{W})$ dapat dilihat pada TABEL 4.

TABEL 4. Hubungan kecepatan sudut dengan perbandingan Q/W kalorimeter aluminium pejal

\begin{tabular}{ccccc}
\hline No. & $\begin{array}{c}\text { Jumlah putaran } \\
(\mathbf{N})\end{array}$ & $\begin{array}{c}\text { Kecepatan sudut } \\
(\mathbf{r p m})\end{array}$ & $\begin{array}{c}\text { Perubahan Suhu } \\
\left({ }^{\circ} \mathbf{C}\right)\end{array}$ & $\begin{array}{c}\text { Perbandingan } \\
\mathbf{Q} / \mathbf{W}\end{array}$ \\
\hline 1 & 140 & 70 & 4.5 & $85 \%$ \\
2 & 196 & 98 & 5.7 & $76 \%$ \\
3 & 210 & 105 & 6.6 & $81 \%$ \\
4 & 225 & 113 & 8.3 & $97 \%$ \\
5 & 245 & 123 & 7.2 & $76 \%$ \\
6 & 260 & 130 & 9.1 & $92 \%$ \\
\hline
\end{tabular}

\section{Hukum Joule}

Seperti halnya tara kalor mekanik, dilakukan analisis faktor/besaran yang berpengaruh terhadap energi listrik $\mathrm{W}=\mathrm{V}$ I $\mathrm{t}$ dan energi panas $\mathrm{Q}=\mathrm{m} \mathrm{c} \Delta \mathrm{T}$, agar $\mathrm{Q} / \mathrm{W}$ akan mendekati nilai 1 bahkan sama dengan 1. Untuk pengamatan hukum Joule kumparan memanaskan air selama 120 detik, dengan pendinginan 240 detik, massa air tetap dengan arus yang melalui kumparan diubah sebanyak 6 kali seperti pada TABEL 5 .

TABEL 5. Data Pengamatan Perubahan Energi Listrik menjadi Energi Panas

\begin{tabular}{cccccccccc}
\hline NO. & $\begin{array}{c}\text { TR } \\
\left({ }^{\mathbf{0}} \mathbf{C}\right)\end{array}$ & $\mathbf{T 0}\left({ }^{\mathbf{0}} \mathbf{C}\right)$ & $\mathbf{T 1}\left({ }^{\mathbf{0}} \mathbf{C}\right)$ & $\mathbf{T} 2\left({ }^{\mathbf{0}} \mathbf{C}\right)$ & $\begin{array}{c}\Delta \mathbf{T} \\
\left({ }^{\mathbf{0}} \mathbf{C}\right)\end{array}$ & $\mathbf{I}(\mathbf{A})$ & $\mathbf{V}($ volt $)$ & t (sekon) & massa air $(\mathbf{g r})$ \\
\hline 1 & 25,4 & 25,6 & 25,8 & 25,7 & 0,24 & 0,5 & 1,4 & 120 & 100 \\
2 & 25,4 & 23,9 & 24,6 & 24,2 & 0,93 & 1 & 2,6 & 120 & 100 \\
3 & 25,4 & 24,2 & 25,9 & 25,8 & 1,66 & 1,5 & 3,8 & 120 & 100 \\
4 & 25,4 & 23,9 & 26,7 & 26,6 & 2,7 & 2 & 5 & 120 & 100 \\
5 & 25,4 & 23,8 & 27,1 & 26,8 & 3,3 & 2,5 & 6,4 & 120 & 100 \\
6 & 25,4 & 24 & 27,8 & 27,4 & 3,8 & 3 & 8 & 120 & 100 \\
\hline
\end{tabular}




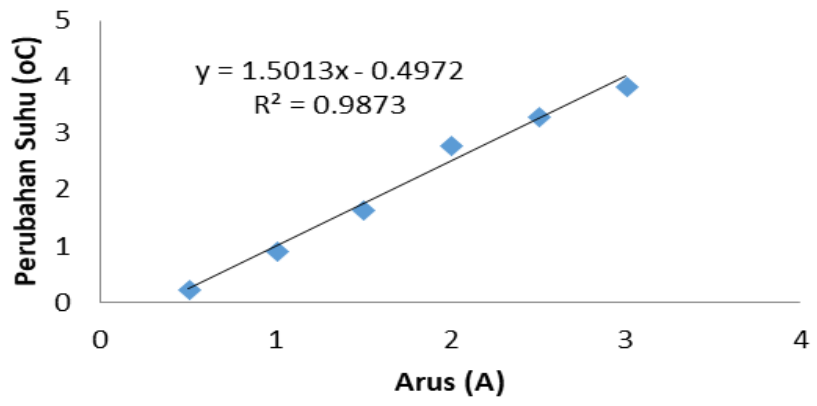

GAMBAR 6. Hubungan Arus Listrik dan Perubahan suhu

GAMBAR 6 menunjukkan hubungan antara arus listrik yang diberikan pada kalorimeter dengan perubahan suhu yang terjadi. Dari persamaan (4) terlihat bahwa arus berbanding lurus dengan usaha yang hasilkan. Hubungan antara arus listrik dengan perubahan suhu bersifat linier dengan $R^{2}=0,987$. Namun kenaikan suhu yang linier dengan arus tidak menghasilkan hubungan linier dengan perbandingan kalor yang dihasilkan (Q) dengan energi listrik yang diberikan (W). Besar perbandingan $\mathrm{Q} / \mathrm{W}$ untuk setiap harga arus yang diberikan dapat dilihat pada TABEL 6.

TABEL 6. Perbandingan $\mathrm{Q} / \mathrm{W}$ untuk beberapa harga arus yang diberikan

\begin{tabular}{cccccc}
\hline NO. & $\mathbf{I}(\mathbf{A})$ & $\Delta \mathbf{T}\left({ }^{\circ} \mathbf{C}\right)$ & $\mathbf{Q}(\mathbf{J})$ & $\mathbf{W}(\mathbf{J})$ & $\mathbf{Q} / \mathbf{W}$ \\
\hline 1 & 0.5 & 0.24 & 72 & 84 & $86 \%$ \\
2 & 1 & 0.93 & 285 & 312 & $91 \%$ \\
3 & 1.5 & 1.66 & 640 & 684 & $94 \%$ \\
4 & 2 & 2.7 & 1174 & 1200 & $98 \%$ \\
5 & 2.5 & 3.3 & 1789 & 1920 & $93 \%$ \\
6 & 3 & 3.8 & 1615 & 2880 & $56 \%$ \\
\hline
\end{tabular}

Ketidaklinieran antara arus yang diberikan dengan ratio Q/W disebabkan oleh beberapa faktor. Hal ini disebabkan karena kalorimeter yang digunakan tidak murni bersifat adiabatik akibatnya ketika diberikan harga arus yang besar, suhu air pada kalorimeter cepat naik dan terjadi penyerapan suhu oleh lingkungan semakin besar. Sedangkan saat pemberian arus rendah, lebih kecil dari 1,5 A, suhu air pada kalorimeter mengalami kenaikan dengan waktu yang cukup lama. Dari hasil analisis ini disarankan apabila menggunakan arus yang kecil, waktu pemanasan perlu diperbesar.

Dengan demikian dapat direkomendasikan pemberian harga arus yang optimum adalah pada pemberian arus sebesar 1,5 $\mathrm{A}-2,5 \mathrm{~A}$, dengan ratio $\mathrm{Q} / \mathrm{W}$ mendekati $100 \%$.

\section{PENUTUP}

Untuk mendapatkan perubahan energi mekanik menjadi energi panas yang optimum, kalorimeter tembaga memerlukan kecepatan sudut lebih besar dibandingkan dengan calorimeter aluminium pejal. Kecepatan sudut optimum kalorimeter tembaga kosong adalah $137 \mathrm{rpm}$, tembaga pejal $132 \mathrm{rpm}$, sedangkan aluminium pejal sebesar $113 \mathrm{rpm}$. Hal ini sesuai dengan besarnya kapasitas panas bahan kalorimeter yang digunakan.

Dari percobaan hukum Joule diperoleh ketidaklinieran antara arus yang diberikan dengan ratio Q/W disebabkan oleh beberapa faktor. Hal ini disebabkan karena kalorimeter yang digunakan tidak murni bersifat adiabatik akibatnya ketika diberikan harga arus yang besar, suhu air pada kalorimeter cepat naik dan terjadi penyerapan suhu oleh lingkungan semakin besar. Sedangkan saat pemberian arus rendah, lebih kecil dari 1,5 A, suhu air pada kalorimeter mengalami kenaikan dengan waktu 
yang cukup lama. Dari hasil analisis ini disarankan apabila menggunakan arus yang kecil, waktu pemanasan perlu diperbesar. Dengan demikian dapat direkomendasikan pemberian harga arus yang optimum adalah pada pemberian arus berkisar antara $1,5 \mathrm{~A}-2,5 \mathrm{~A}$, dengan ratio $\mathrm{Q} / \mathrm{W}$ mendekati $100 \%$.

\section{UCAPAN TERIMAKASIH}

Terimakasih kepada Politeknik Negeri Bandung melalui Unit Penelitian dan Pengabdian kepada Masyarakat (UPPM) Politeknik Negeri Bandung yang telah mendanai penelitian ini dan kepada rekan-rekan pengajar Fisika Terapan Polban yang telah turut berkonstribusi dalam penelitian ini.

\section{REFERENSI}

[1] H. Kunlestiowati, "Analisis penyimpangan konversi energi listrik menjadi kalor pada perangkat eksperimen Hukum Joule”, JRKPF UAD, Vol. 5, No.1, pp 34-39, 2018.

[2] "Physics Experiments," Germany, LD Didactic GmbH, 2017, p. 72.

[3] Halliday, Resnick, Walker, "Temperature, Heat, and the First Law of Thermodynamics" in Fundamental of Physics, 6th ed. New Delhi, India: Wiley, 2006, pp 425-448.

[4] Emma Carlson Berne "Heat Energy". The Rosen Publishing Group. p. 18. ISBN 978-14488-9886-2, p. 18, Januari 2013.

[5] Serway, R.A. dan Jewett, John W, Fisika Untuk Sains dan Teknik. Jakarta :Salemba Teknika, 2009.

[6] Tipler, Paul A,. "Perpindahan Panas" in Fisika untuk Sains dan Teknik. Jakarta: Erlangga, 2005.

[7] Panduan Praktikum Fisika, Politeknik Negeri Bandung, Bandung, 2012, pp 34-39.

[8] Suryani dan Santosa, "Pengukuran Konstanta Pendinginan Newton",. Prosiding Seminar Nasional Sains dan Pendidikan Sains IX, Salatiga: UKSW, Vol 5, No.1, p. 386-390, 2014. 